\title{
OS MANUAIS DO PROFESSOR DAS COLEÇÕES DIDÁTICAS E OS REFERENCIAIS CURRICULARES COMO FONTES DE PESQUISA EM EDUCAÇÃO ${ }^{1}$
}

\author{
André Luiz Paulilo ${ }^{2}$ \\ Universidade Estadual de Campinas \\ andre.paulilo@pq.cnpq.br
}

Recepción: 27/03/2011

Evaluación: 09/05/2011

Aceptación: 22/06/2011

Artículo de Revisión

\section{RESUMO}

Este artigo tem como finalidade apresentar resultados de uma pesquisa acerca do ensino de história. Este estudo busca mostrar os manuais do professor e os referenciais curriculares como fontes de pesquisa em educação. Trata-se de discussão fundamentada na idéia de que, no Brasil, os manuais do professor e os referenciais curriculares trazem representações acerca do ensino. Argumenta-se que os paradigmas organizadores do discurso sobre as práticas de ensino nos manuais didáticos e nas orientações curriculares têm composto bases teóricas e metodológicas específicas. Assim, o artigo expõe e analisa alguns aspectos desses tipos de impressos escolares.

Palavras chave: Revista História da Educaşão Latino-americana, ensino de história, manuais do professor, ensino fundamental, representações.

\footnotetext{
${ }_{2}^{1}$ Esta pesquisa foi financiada pelo CNPq.

Doutor em Educação. Professor da Universidade Estadual de Campinas.
} 


\title{
EL MAESTRO DE LOS MANUALES Y LAS \\ COLECCIONES DE LA ENSEÑANZA DE LA ESTRUCTURA DEL CURRÍCULO COMO FUENTES DE LA INVESTIGACIÓN EN LA EDUCACIÓN
}

\author{
André Luiz Paulilo \\ Universidade Estadual de Campinas \\ andre.paulilo@pq.cnpq.br
}

\begin{abstract}
RESUMEN
Este artículo tiene como objetivo presentar los resultados de una encuesta sobre la enseñanza de la historia. Tenemos la intención de mostrar el manual del profesor y las estructuras curriculares como fuentes de la investigación educativa. Es motivado la discusión sobre la idea de que en Brasil, los manuales del profesor y las estructuras curriculares traer representaciones acerca de la enseñanza. Se argumenta que los organizadores de los paradigmas del discurso sobre las prácticas de enseñanza en los libros de texto y los lineamientos curriculares se han concretado las bases teóricas y metodológicas. Así, el artículo presenta y analiza algunos aspectos de este tipo de escuela impresa.
\end{abstract}

Palabras clave: Revista Historia de La Educación Latinoamericana, enseñanza de la bistoria, libros del maestro, la escuela primaria representante.

\section{THE TEACHER OF THE MANUALS AND TEACHING COLLECTION OF THE CURRICULUM STRUCTURE AS SOURCES OF RESEARCH IN THE EDUCATION}

\author{
André Luiz Paulilo \\ University Estadual de Campinas \\ andre.paulilo@pq.cnpq.br
}

\begin{abstract}
This article aims at presenting the results of a survey on the education of the history. We have the intention of showing the manual of the teacher and the currucular structures as sources of the educational research. The discussion is motivated on the idea of Brazil as a such,
\end{abstract}


the manuals of the teacher and the curricular structures to bring representations brings over of the education. There is argued that the organizers of the paradigms of the speech on the education practices in the books of text and curriculum limits have made concrete the theoretical and methodological bases. This way, the article presents and analyzes some aspects of this type of printed school.

Key words: Journal of Latin American Education History, teaching of the bistory, teacher's books, Primary school representation.

\section{INTRODUÇÃO}

Constituída a partir de um modelo interpretativo que privilegia a análise das práticas docentes e o estudo da história das disciplinas escolares ${ }^{3}$, esse estudo quis compreender as representações que os manuais dos livros didáticos de história e as propostas de reorientação curricular do Estado de São Paulo e da cidade de São Paulo veiculam sobre o ensino de História. No decorrer dessa pesquisa, a atenção se cingiu ao inventário das estratégias empreendidas para impor aos docentes uma representação do "bom" ensino, para sugerir modelos de conduta, para desqualificar certos procedimentos .

A investigação dos esquemas de percepção do trabalho docente e das atribuições do ensino de História nos manuais do professor dos livros didáticos e nos referenciais curriculares do Estado de São Paulo e da sua capital pretendeu entender as ações que se espera dos docentes desta disciplina. O principal problema então abordado foi o das atuais demandas sociais junto aos professores de história. Em meio à extensão desmesurada dos campos que se lhes pede lavrar para seus alunos, a pesquisa trata de algumas das principais maneiras pelas quais a docência de história costuma ser vista e representada.

${ }^{3}$ Cf. BITTENCOURT, Circe. (2003): "Disciplinas escolares: história e pesquisa", in História das disciplinas escolares no Brasil: contribuições para o debate. OLIVEIRA, M. A. T.; RANZI, S. M. F. (org.). Bragança Paulista, EDUSF, pp. 9-38.

Para uma definição mais precisa do conceito de representação ver CHARTIER, Roger. (2002): À beira da falésia: a história entre certezas e inquietude. Porto Alegre, Editora da Universidade/UFRGS. 
A tarefa que pretendi realizar com a pesquisa Perspectivas sobre a História Ensinada, por um lado, utilizou como fonte os manuais de uso que acompanham o exemplar do professor dos livros didáticos recomendados no Programa Nacional do Livro Didático de 2008 (PNLD-2008). Por outro lado, dedicou-se à análise das atuais propostas curriculares de História impressas e distribuídas pelas secretarias de educação do Estado de São Paulo e da Prefeitura da capital. Ao discutir exemplos concretos de configurações graças às quais o ensino de história é percebido, tentei inventariar os traços e indícios de práticas de controle doutrinário do trabalho educativo que ainda permanecem pouco estudados.

Os manuais do professor e os referenciais curriculares que se analisou não são apenas marcados pelo debate sobre o ensino de história surgido no período final da ditadura civil-militar. Eles testemunham também a presença de correntes pedagógicas que visam teorizar as modalidades de aprendizagem. Desse modo, também repercutem as preocupações pedagógicas com a prática do ensino de História e preconizam o protagonismo do aluno nos processos de aprendizagem. Do ponto de vista da metodologia do ensino de História, as mudanças indicadas na maneira de ensinar também foram uma questão para a pesquisa.

O propósito deste estudo é discutir a pesquisa realizada nesses impressos de edição recente. Trata-se de um esforço de compreensão das possibilidades de estudo dos textos escolares dirigidos aos professores. Nesse sentido, apresento uma reflexão sobre a abordagem que empreendi a fim de enfocar o trabalho de análise dessas fontes para o exame das atuais demandas do ensino de história ${ }^{5}$.

\section{Para uma compreensão das práticas de ensino}

Os procedimentos desta pesquisa foram constituídos a partir do inventário dos manuais de uso que acompanham o exemplar do professor dos livros didáticos de história recomendados pelo PNLD2008. Visando compreender como o ensino de história é percebido nesse tipo de impresso, a pesquisa principalmente enfatizou os dispositivos que Roger Chartier identifica quando relaciona o texto

\footnotetext{
${ }^{5}$ É complementar a este estudo a análise publicada em PAULILO, André Luiz. (2010): Os modos de enunciação nos manuais de ensino para professor de história. Topoi, Vol. 11, N 21 , pp. 283-302.

CHARTIER, Roger. (2007): O mundo como representação. Estudos Avançados, 11 (5), pp. 173-191.
} 
e a sua materialidade ${ }^{6}$ e a perspectiva que Mikhail Bakhtin propõe sobre os gêneros do discurso . Assim, não só interessou identificar os dispositivos por meio dos quais os manuais do professor consolidam uma dada representação do ensino e do professor de história e as estratégias simbólicas que determinam posições e relações capazes de atribuir uma espécie de identidade para esse grupo profissional. Também importou compreender as peculiaridades constitutivas do gênero textual, a concepção de destinatário e os modos de enunciação dos manuais de uso do professor.

Noutro plano de preocupações, cabe explicitar a utilidade das posições que Ivor Goodson mantém em relação à história do currículo. Segundo Goodson, não só o currículo, mas qualquer roteiro oficial de ensino, "é um testemunho visível, público e sujeito a mudanças, uma lógica que se escolhe para, mediante sua retórica, legitimar uma escolarização" . Dessa perspectiva, as propostas oficiais de reorientação curricular podem ser vistas como indícios dos valores e objetivos promovidos junto às instituições escolares. Esse modo de proceder esta relacionado com a história social do currículo. Muito em razão disso, trata-se de uma compreensão que considera na luta para se definir um currículo, as sociopolíticas e o discurso de ordem intelectual então envolvidos. A série de publicações com que as secretarias de educação do Estado de São Paulo e da Prefeitura da sua capital têm reorientado a proposta curricular de suas redes de ensino foi objeto de uma análise nessa direção.

A partir deste terreno de trabalho em que se enredam o texto e a sua materialidade, realizei o tratamento analítico dos manuais de uso do professor e dos referenciais curriculares editados pelo governo do Estado e pela Prefeitura da capital ${ }^{11}$. A leitura de todo o material envolveu estratégias de levantamento de critérios de seleção dos conteúdos, metodologia, recursos didáticos e de linguagem e, principalmente, de atividades e procedimentos.

${ }_{8}^{7}$ BAKHTIN, Mikhail. (2006): Estética da criação verbal. São Paulo, Marins fontes.

${ }_{9}^{8}$ CHARTIER, Roger. (2007): óp., cit, p.184.

${ }_{10}$ BAKHTIN, Mikhail. (2006): óp., cit, pp. 283-302.

${ }_{11}$ GOODSON, Ivor. (1995): Currículo: teoria e história. Petrópolis-RJ, Vozes, p. 21.

11 A pesquisa foi, sobretudo, fundamentada nas aproximações entre o texto e sua materialidade que se realiza no estudo da cultura escolar feito por VIDAL, Diana. (2005): A cultura escolar. Campinas, Autores Associados. 
Inicialmente, seguindo um padrão definido por Klaus Bergmann, identifiquei os pressupostos, condições e metas da aprendizagem, os métodos e a possibilidade de estruturação dos conteúdos e as técnicas e materiais de ensino e as várias possibilidades da representação da História, seja no ensino ou nos ambientes fora da escola ${ }^{12}$. A seguir, tracei os contornos dos dados e comparei os resultados. Após organizar os esquemas de percepção e a concepção de ensino das diferentes coleções recomendadas pelo PNLD-2008 na área de História optei por duas tópicas. A primeira diz respeito ao inventário do instrumental metódico e teórico da História, dos critérios para seleção dos conteúdos e das orientações e atitudes assumidas por tais obras. A segunda cingese ao cotejo das rotinas de trabalho sugeridas e que se solicita realizar. Principalmente, discuti o Manual do Professor como peça de prescrição de certezas metodológicas e controle técnico da prática de ensino.

Repeti esse procedimento ao analisar as Propostas Curriculares publicadas entre 2006 e 2008 pelas secretarias de educação do governo de São Paulo e da Prefeitura da capital. Assim, a partir do material que designa as propostas para o ensino de história nas séries finais do ensino fundamental, examinei esse material no encalço das estratégias e atividades que sistematizam. Debrucei-me sobre os referenciais curriculares e as expectativas de aprendizagem tendo em vista as suas relações com as recentes iniciativas de gratificação, promoção e contratação de professores na cidade e no Estado de São Paulo ${ }^{13}$. Minha principal preocupação foi mostrar que hoje medidas de ordem administrativa seguem às orientações curriculares e prescrições acerca da intervenção e mediação do professorado objetivando garantir o êxito das propostas por meio da política de remuneração e dos critérios de arregimentação de novos professores.

A compreensão de toda a série de manuais e orientações também envolveu a análise do Edital de convocação para inscrição no processo de avaliação e seleção de obras didáticas a serem incluídas no Guia de Livros Didáticos para os anos finais do ensino fundamental, o Guia de Livros Didáticos PNLD 2008 - História, as Matrizes de referência para a avaliação, Ciências Humanas; Geografia e História; ensino fundamental e médio e a Resolução SEESP-80. Assim, tanto quanto o estudo da reorientação curricular, a abordagem

\footnotetext{
${ }^{12}$ Cf. BERGMANN, Klaus. (1989): "A história na reflexão didática”, em Revista Brasileira

de História. São Paulo, V. 9, Nos 19, pp. 29-42.

Essa documentação está disponível também em "www.educacao.sp.gov.br" e "www. educacao.prefeitura.sp.gov.br".
} 
dos manuais de uso dos livros didáticos de História procurou articular as recomendações de procedimento às diretrizes governamentais que a regulamentam.

Ao fundo desse esforço, as preocupações com os discursos para o professor de História completam a análise das representações sobre a docência dessa disciplina na escola. A partir das considerações de Bakhtin a respeito das condições de diálogo que também o ato de fala impresso cria entre o autor, seus pares e o leitor, procurei entender os vínculos concretos da comunicação verbal com a situação, o lugar de trabalho dos professores. Nessa tarefa, os estudos de José Luís Fiorin ${ }_{17}^{14}$, John Austin ${ }^{15}$, John Searle ${ }^{16}$, Greimas e Marilena Chauí foram auxílios significativos. A observação das categorias da enunciação na análise, a atenção à força elocutória dos atos de fala e a noção de discurso competente resultaram dessa opção por autores que estudaram as palavras como ações em um contexto político, social e intelectual. Sob esse ponto de vista, a investigação inventariou os modos de enunciação em termos das suas estratégias para conferir crença e crédito às formas institucionalizadas através das quais "representantes" encarnam uma autoridade competente. Sobretudo assim, ocupou-se das configurações graças às quais a prática do ensino de história é percebida ${ }^{19}$.

\section{As práticas de controle dos saberes docentes}

Conforme se esperava, a análise dos discursos de intelectuais, autoridades e autores de livros didáticos acerca do ensino de História percebe nos subsídios para o docente, práticas de controle doutrinário do trabalho educativo que ainda permanecem pouco conhecidas.

Primeiramente, as operações de recorte e classificação que produzem as configurações graças às quais a realidade do ensino é representada e apresentada aos professores constituem os instrumentos de dominação simbólica mais usuais na série de publicações aqui estudadas. Envolvem

\footnotetext{
${ }^{14}$ FIORIN, José Luís. (2008): As astúcias da enunciação: as categorias de pessoa, espaço e tempo. $2^{\mathrm{a}}$ ed. São Paulo, Ática, p. 45.

AUSTIN, John. (1990): Quando dizer é fazer. Porto Alegre, Artes Médicas e (1993) Quando dizer é fazer. Porto Alegre, Artes Médicas, p. 67.

SEARLE John. (1981): Os actos de fala: um ensaio de filosofia da linguagem. Coimbra, Livraria Almedina. (1995): Expressão e significado: estudos da teoria dos atos de fala São Paulo, Martins Fontes.

${ }_{18}$ GREIMAS, Algirdas Julien. (1973): Semântica estrutural. São Paulo, Cultrix, Edusp.

${ }_{19}^{18}$ CHAUÍ, Marilena. (1989): Cultura e democracia. São Paulo, Cortez, p. 56.

${ }^{19}$ Ver também CHAUÍ, Marilena. (1989): óp., cit, p. 15.
} 
os modos e as modalidades da enunciação do que é requerido fazer, os protocolos considerados pertinentes para satisfazer as exigências da disciplina e a eficácia em fazê-los reconhecer como necessários. Nesse sentido, a prescrição, o uso dos modos imperativos do verbo ou o desejo de legitimar uma prática pela escrita sugerem a superioridade intrínseca do que pode ser regulado com antecedência sobre as providências decididas no momento da ação.

Depois, o lugar e as circunstâncias em que esse discurso é instituído e pode ser proferido afirmam a competência daqueles a quem a burocracia ou organização reconhece como tendo o direito de falar e a autoridade sobre o saber-fazer. A noção de competência em que Marilena Chaui ${ }^{20}$ e Claude Lefort ${ }^{21}$ apóiam suas análises sobre o discurso e o saber especializado permite discutir os manuais de uso dos livros didáticos e os referenciais curriculares como um artifício mediador do conhecimento por meio do qual se procura submeter o professor à linguagem do especialista. Assim, os autores de livros didáticos e os responsáveis pela organização dos referenciais curriculares instauram o pensamento e se exprimem em discursos considerados verdadeiros no interior da disciplina. Seus currículos, as instituições em nome das quais atuam e o modo como se servem das regras, das definições e técnicas do ofício garantem tratar-se de um especialista.

Segue que fazer reconhecer, exibir o que seria próprio da maneira de ensinar a História, implica explorar de maneira privilegiada os modos e as modalidades, os meios e os procedimentos pelos quais se pode dirigir ao docente para dizer-lhe a verdade sobre seu ofício. Conforme pensava Foucault, o ato de escrever tal como está hoje institucionalizado no livro, no sistema de edição e no personagem do escritor coage pelo caráter intransitivo que o escritor empresta ao seu discurso, pelo regime de divulgação dos editores e pelas formas de apropriação que o livro encerra $^{22}$. O texto, como atualmente as videoconferências, os sítios eletrônicos e o cd-rom, envolve a autoridade daquele que escreve ou fala ao aparelho formal da enunciação. Invariavelmente, a produção dos referenciais curriculares e dos manuais de uso do livro didático confia aos teóricos a produção do conhecimento e aos que atuam na

${ }_{21}^{20}$ CHAUÍ, Marilena. (1989): óp., cit, p. 15.

${ }^{21}$ LEFORT, Claude. (1983): A invenção democrática: os limites da dominação totalitária. São Paulo, Brasiliense.

FOUCAULT, Michel. (1998): A ordem do discurso. São Paulo, Loyola. 
prática a tarefa de ser eficazes e, portanto, tem sido um meio importante de consagrar a oposição teoria-prática. A despeito de articular a oferta pedagógica de um autor e a oferta comercial de um editor ou de investir de autoridade os grupos e indivíduos que "vendem" suas soluções no mercado político ou acadêmico os referenciais e os manuais encerram escolhas compatíveis com a percepção que os especialistas têm das dinâmicas de aprendizagem.

Também a utilização de pequenas fórmulas correntes, sejam slogans ou jargões, é um meio de reiterar regras ${ }^{25}$. Os estereótipos no discurso para e sobre professores indicam o que há de habitual no ofício, as formas relativamente regularizadas de exercer a docência, reforçadas pelo uso e pelas circunstâncias. Segundo Barthes, trata-se de palavras repetidas como se fosse natural, sem entusiasmo: "a via atual da verdade, o traço palpável que faz transitar o ornamento inventado para a forma canonical, coercitiva, do significado" ${ }^{27}$. Dessa perspectiva, a proclamação insistente da autonomia do professor, da interdisciplinaridade e do ensino voltado ao interesse do aluno e para a formação de cidadãos torna-os evidentes por si. A manobra tem servido para solidificar slogans e fórmulas correntes de pensar o ensino e espessá-los ao longo do discurso, ignorando sua própria insistência, pretendendo a consistência ${ }^{28}$.

Enfim, associar o salário dos professores a seu desempenho em termos de resultados de concurso sobre a proposta curricular ou segundo os resultados dos exames dos seus alunos fornece o incentivo legal para as escolas seguirem esses referenciais ${ }^{29}$. Programas do tipo "Qualidade da Escola" e "Qualidade na Escola" fazem da promoção e da gratificação um meio de implantar a orientação curricular que as autoridades políticas desejam. Esses programas dispõem de medidas para fazer do currículo o instrumento de uma autêntica política de pessoal. De um modo geral, as políticas sobre a escola referentes á mudança, aos currículos e à avaliação sustentam toda uma legislação que premia a

\footnotetext{
${ }^{23}$ CHARTIER, Anne-Marie. (2007): Práticas de leitura e escrita: história e atualidade. Belo Horizonte, Autêntica, p. 70.

BALL, Stephen. (1998): "Big policies/small world: an introduction to international perspectives in educational policy". Comparative Education. Pen State, V. 34, N², pp. 15-130.

${ }_{26}^{25}$ SCHEFFLER, Israel. (1974): A linguagem da educação. São Paulo, EDUSP, Saraiva.

${ }^{26}$ Conferir definição de esteriótipos em BAKHTIN, Mikhail. (1992): Marxismo e filosofia da linguagem: problemas fundamentais do método sociológico na ciência da linguagem. ${ }_{27}^{\mathrm{a}}$ Ed. São Paulo.

${ }_{28}^{27}$ BARTHES, Roland. (2002): O prazer do texto. $3^{\text {a }}$ edição. São Paulo, Perspectiva, p. 52. ${ }_{29}$ Ibídem., p. 53.

${ }^{29}$ Experiências desse tipo foram estudadas por GOODSON, Ivor. (2008): As políticas de currículo e de escolarização. São Paulo.
} 
docilidade e obediência quanto à realização da proposta, desencorajando a inventividade e criatividade. A atual reorientação curricular do Estado de São Paulo faz da espécie de prestação de contas que são os processos avaliativos para promoção, gratificação e admissão uma estratégia de controle da ação educativa e liberdade do professor.

\section{Orientação didática e poder}

À perspectiva de estudo que esta pesquisa pretendeu desenvolver não importou aprofundar a discussão da série de prioridades e hipóteses que estão no centro dos debates sobre as finalidades do ensino de História na escola brasileira atualmente ${ }^{30}$. A sua principal tarefa foi compreender os dispositivos de controle doutrinário do professor que constituem os recentes referenciais propostos para se lecionar História. Por essa razão, o esforço de compreensão se concentrou nas representações elaboradas sobre os métodos de ensino de História nos manuais de uso dos livros didáticos recomendados pelo PNLD da área e nos referenciais curriculares do Estado de São Paulo e da Prefeitura da capital. Mais que das matrizes das práticas construtoras da docência em História a abordagem trata das indicações metodológicas acerca do ensino nessa área, das práticas de sala de aula recomendadas e da demanda da $_{31}$ sociedade sobre o trabalho docente na área de História ${ }^{31}$.

Os resultados desse empreendimento percebem no Manual do Professor uma pista para a investigação sobre o como se pensa a prática do ensino de história. Fundamentalmente, enfatiza que esse tipo de texto trata das estratégias de organização e método do ensino da matéria. Isso não significou dizer que ele efetivamente organiza e institui uma metodologia de ensino, mas sim que é parte das condições de sua emergência, inserção e funcionamento. Também debrucei-me sobre os esquemas de percepção atualmente formalizados nas propostas de reorientação curricular de São Paulo sobre o ensino de História ${ }^{32}$. Com o

\footnotetext{
${ }^{30}$ Nesse sentido preciso de análise ver os estudos de BITTENCOURT, Circe. (2004): Ensino de História: fundamentos e métodos. São Paulo: Cortez. (Coleção Docência em Formação: série Ensino Fundamental).

Acerca dessa preocupação com a relação entre as práticas do ensino de história e as demandas da sociedade ver BORNE, Dominique. (1998): Comunidade de memória e rigor crítico, in BOUTIER, J; JULIA, D. (org.). Passados recompostos: campos e canteiros da História. Rio de Janeiro, UFRJ; FGV, pp.133-141.

Para uma interpretação de outro tipo daquela construída aqui ver CIAMPI, Helenice [et. al].(2008): O currículo bandeirante: a proposta curricular de história no estado de São Paulo, em Revista Brasileira de História. São Paulo, Vol. 29, № 58, pp. 361-382, 2009.
} 
intuito de compreender suas práticas e objetivos, a abordagem discute os regimes de legibilidade e intencionalidade dos enunciados organizados no interior das secretarias de educação do governo do Estado de São Paulo e da Prefeitura da capital, os processos que os produziram e as suas estratégias discursivas.

Conforme adverte Goodson, se os especialistas em currículo, os historiadores e sociólogos da educação ignoram, em substância, a história e a construção social do currículo, mais fáceis se tornam a mistificação e a reprodução das formas tradicionais de currículo ${ }^{33}$. Talvez nesse sentido, o foco nas representações que especialistas e autoridades políticas fazem das práticas dos professores e dos processos que as constituem possa contribuir com uma perspectiva de análise.

Os indícios que procurei reunir para compreender as maneiras como a docência da história tem sido vista e representada deram-me boas pistas acerca das estratégias utilizadas para conferir crença e crédito ao que se diz ser a verdade sobre a prática desse ofício. O motivo desta pesquisa veio de um incômodo com as preocupações de momento com o trabalho do professor de história e diz respeito aos atuais esforços de qualificação docente. Daí a hipótese que fixou o lugar da investigação que realizei: perante o professor há muitos que lhe pretendem dizer qual é a verdade muda do seu ofício. Portanto, o impulso para esta pesquisa envolveu a ideia de que a ação exige que as pessoas falem por sua conta. Sobretudo, Anne-Marie Chartier mostrou que quando o professores se põem a falar, eles próprios têm um discurso sobre o que são e o que deveriam ser as práticas ${ }^{34}$. Para os propósitos deste trabalho, esse problema do direito, ou melhor, da autoridade para dizer foi central.

Fundamentalmente, abordei as orientações de ensino dos Manuais do Professor que acompanharam os livros didáticos de história recomendados pelo PNLD-2008 e das propostas curriculares de História do governo do Estado de São Paulo e da prefeitura da sua capital com vistas a perceber "quem" enuncia e como induz as escolhas didáticas e pedagógicas. Um primeiro conjunto de conclusões de pesquisa decorreu desta atenção ${ }_{35}$ aos "autores" dos instrumentos de auxílio pedagógico do professor .

${ }_{34}^{33}$ GOODSON, Ivor. (1995): óp., cit, p. 27.

${ }_{35}^{34}$ CHARTIER, Anne-Marie. (2007): óp., cit, pp. 203-204.

${ }^{35}$ Essa atenção foi baseada nas indicações de FOUCAULT, Michel. (1998): óp., cit, 
Embora a experiência docente na educação básica seja uma credencial explorada pelos autores de livros didáticos, a instituição de formação e a posição no campo do ensino superior prevalecem como indicativos de autoridade. Como ocorre nos livros didáticos, nas Orientações Curriculares a experiência docente também é referenciada: reconhece-se a participação ou a consulta aos docentes da rede de ensino no processo de elaboração dos documentos. Contudo, é a condição de assessor ou de especialistas responsáveis que define os lugares de procedência dos discursos reconhecidos e legitimados. Tal prática confirma que as publicações institucionais envolvem arranjos de função e expressam autoridade e prestígio mobilizando estratégias de legitimidade e representação. Nesse sentido, a composição da série de orientações didáticas publicadas pela SEE-SP e pela SME da capital do Estado resultou tanto de uma prática de ordenação e controle dos modos de reconhecimento e veracidade dos discursos a respeito do ensino de história quanto dos arranjos de nomeação das equipes de especialistas.

A espécie de divisão do trabalho que assim a edição escolar e a contratação de trabalho especializado de orientação curricular pelo poder público estabelecem no sistema de educação impõe papéis prescritos aos docentes. $\mathrm{Na}$ lógica que Anne Marie Chartier percebe nessa forma de organizar as práticas do ensino, "os programas e os textos oficiais definem as finalidades, e os conteúdos da aprendizagem no âmbito da escola ${ }_{36} \mathrm{e}$ os professores os colocam em prática, por meio dos livros didáticos" ${ }^{36}$.

Em relação aqueles que se encarregam da elaboração do material didático ou de orientação, o exercício da docência se reduz às tarefas prático-empíricas. Nesse sentido, a autoridade dos especialistas na elaboração dos discursos sobre a prática docente é confirmada à custa da desvalorização dos professores como produtores ou geradores de conhecimento pedagógico. Conforme compreendem Nóvoa e Viñao Frago, a consolidação, afirmação e reconhecimento social, político e econômico do saber científico sobre a educação tem excluído o dito saber prátiço, de base empírica, como espaço de produção do saber pedagógico $^{37}$. Nas publicações que analisei, a associação entre especialistas

\footnotetext{
${ }_{37}^{36}$ Ibídem., p. 148.

NÓVOA, Antônio. (2002): "A imprensa de educação e ensino: concepção e organização do Repertório Português", in CATANI, D. B.; BASTOS, M.H.C. (orgs). Educação em revista: a imprensa periódica e a história da educação. São Paulo: Escrituras, pp. 11-31; VIÑAO FRAGO, Antônio. (2001): "Fracassam as reformas educativas? A resposta de um historiador" in SBHE. Educação no Brasil: história e historiografia. Campinas. Autores Associados, p. 41.
} 
e discursos formados no campo da pesquisa acadêmica são indícios de um processo desse mesmo tipo. Predominantemente foram especialistas das universidades de São Paulo e de Campinas e da Pontifícia Universidade Católica que conduziram e assessoraram a elaboração das orientações curriculares para a área de História nas secretarias de educação do Estado de São Paulo e do município da sua capital. O processo de seleção dos livros recomendados pelo PNLD resulta de uma avaliação entre os pares que, feito no âmbito dos departamentos de história e educação das universidades públicas, tem credenciado cada vez mais produções organizadas segundo os critérios da pesquisa universitária ${ }^{38}$.

Foucault nota que por meio do direito do sujeito que fala se dá a sua ligação com o poder . Principalmente, a prescrição, o uso dos modos imperativos do verbo ou o desejo de legitimar uma prática pela escrita sugerem a prevalência do que pode ser regulado com antecedência sobre as providências decididas no momento da ação. No caso das publicações estudadas, certo número de operações de recorte e classificação produziu as configurações graças às quais a realidade do ensino foi representada e apresentada aos professores. Os modos e as modalidades da enunciação do que é requerido fazer, os protocolos considerados pertinentes para satisfazer as exigências da disciplina e a eficácia em fazê-los reconhecer como necessários referem-se a um professor que poderia realizar corretamente a orientação. Esse é o cerne do caráter intransitivo que os escritores emprestam aos seus discursos nessas publicações instrucionais. Pelo contrário, quando os docentes se põem a falar e a agir em seu nome, eles não opõem uma representação a uma outra, eles não opõem a prática à teoria. Sob as sempre lembradas formas tradicionais de ensino que essas publicações imputam aos professores não se observa apenas o apego a outra organização da aula e da escola ou da metodologia de trabalho, mas, como compreende Foucault, a percepção de um ponto singular onde o poder se exerce às suas custas . Foi dessa perspectiva que busquei compreender em discursos tão específicos quanto os dos manuais do professor e das orientações curriculares as iniciativas para fazer crescer o investimento do professor de história no trabalho de sala de aula.

\footnotetext{
${ }^{38}$ Uma análise mais acurada desse processo de avaliação dos livros didáticos distribuídos pelo Programa Nacional do Livro Didático ver LUCA, T. R.; BEZERRA, H. G. (2006): Em busca da qualidade PNLD História - 1996-2004, in SPOSITO, M. E. B. (org.). Livros didáticos de História e Geografia: avaliação e pesquisa. São Paulo, Cultura Acadêmica, pp. 27-53 e LUCA, T. R.; MIRANDA, S. R. (2004): O livro didático de história hoje: um panorama a partir do PNLD, em Revista Brasileira de História, São Paulo, V. 24, N 48, pp. 123-144.

${ }_{40}^{39}$ FOUCAULT, Michel. óp., cit, pp. 9-10.

FOUCAULT, Michel. (2003): Estratégia, poder-saber. Rio de Janeiro, Forense Universitária, p. 42.
} 
Sobretudo recentemente, nessas publicações, as sugestões de atividade e a indicação de meios para a condução da aprendizagem dão ênfase às práticas de sala de aula. Os manuais do professor dos livros didáticos e as orientações curriculares reúnem um variado repertório de procedimentos e recursos de ensino. Trata-se de impressos de caráter operacional, mais afeitos ao uso no dia-a-dia do que para ser lido e que veiculam um discurso sobre a prática. Nesse sentido, as suas especificações, expectativas e exigências acerca do ensino de história foram compreendidas como expressão de demandas vindas da sociedade e do poder público. Interessou discutir os manuais do professor dos livros didáticos e as orientações curriculares como um elemento das atuais estratégias de formação continuada de professores. $\mathrm{O}$ edital de convocação para inscrição no processo de avaliação e seleção de obras didáticas e as propostas curriculares do governo do estado e da prefeitura de São Paulo consideram esses impressos como peças que auxiliam na atualização do professor e uma contribuição para a sua formação continuada. Assim, o seu estudo me pareceu relevante porque são publicações que oferecem insumos que expressam objetivos práticos e utilitários de ensino. Trata-se de uma série de indicações a respeito da preparação da aula, do seu encaminhamento e do retorno dos resultados e acerca de estratégias educativas e modelos de atividade que importa pelo esforço de veicular um discurso sobre o modo de ensinar junto aos que atuam na prática.

Entre o que se concede e aquilo que se demanda do professor, constata-se que os manuais das coleções didáticas de história e as propostas de reorientação curricular formalizam as configurações por meio das quais a docência e a aprendizagem devem ser percebidas. Ainda que percebida em função das suas atividades mais ordinárias, a docência de história tem sido apresentada nessas publicações sob a perspectiva da eficácia ${ }^{42}$. Segundo o que se pôde ler nelas, o professor de história ajuda a ordenar um discurso sobre o mundo, cria possibilidades de

${ }^{41}$ Cf. BRASIL (MEC-FNDE). (2007): Edital de convocação para inscrição no processo de avaliação e seleção de obras didáticas a serem incluídas no Guia de Livros Didáticos para os anos finais do ensino fundamental. ftp://ftp.fnde.gov.br/web/ editaislicitações/edital_pnld-2008pdf., 63 fls. Acesso: 09 jan. 2007; SÃO PAULO (Município). Concurso público de ingresso para provimento de cargos vagos de professor de ensino fundamental II e médio - classe dos docentes da carreira do magistério municipal. Edital de abertura de inscrições e instruções especiais. http:// fcc.telium.com.br/concursos/pmspd109/ edital_ingresso_pub_240709.pdf. Acesso em 25 jul. 2007 e SÃO PAULO (Estado). Proposta Curricular do Estado de São Paulo: História. São Paulo: SEE, 2008.

Conferir as conseqüências desse discurso nas análises construídas em SILVA, Mônica Ribeiro (2008). Curriculo e competências: a formação administrada. São Paulo, Cortez. 
investigação dos processos históricos locais e dá tratamento didático capaz de facilitar ao aluno o exercício do pensamento livre. O ofício, então, requer preparo para problematizar, para analisar e questionar a realidade de uma atualidade sem tradição ou passado. Nota-se primeiro que a relação de poder expressa pelas obrigações do ofício docente fica muito reduzida aos serviços ordinários. O planejamento, o registro, a orientação das atividades, a correção dos resultados, o estímulo à atenção do aluno, a distribuição dos materiais e organização do trabalho e da apresentação dos alunos em sala são os imperativos cotidianos reiterados ao docente-leitor a cada novo conjunto de temas e atividades. Por outro lado, as finalidades do ensino se estendem desmesuradamente. Além de contribuir para a formação de cidadãos e construir uma ideia clara dos acontecimentos e processos históricos e de sua sucessão no tempo pede-se ao professor de história que também provoque atitudes solidárias de convívio social e tolerância, promova o desenvolvimento do juízo crítico e desenvolva a competência leitora dos seus alunos. Entre outros tantos exemplos, desenvolver habilidades cognitivas como capacidade de análise, inferência, interpretação e síntese e valorizar o patrimônio histórico e cultural de diferentes sociedades tem se associado nos manuais do professor às tarefas impostas pela inclusão de diferentes visões do passado no ensino da história do país e a crítica ao eurocentrismo.

Conforme evidenciou a leitura de todo o conjunto documental, o professor de história que os manuais das coleções didáticas e os documentos de área ostentam não é o mesmo daquele que definem como seu destinatário. Através da análise do discurso dirigido aos docentes nesse conjunto de materiais espero ter mostrado também que a vulgarização do conhecimento histórico especializado tem se valido de uma linguagem representativa das relações mantidas pelas autoridades e especialistas do ensino com os professores. Principalmente, procurei sublinhar os protocolos de autoridade da hierarquia funcional presentes no recorrente uso do modo imperativo dos verbos. Operar o sentido do fazer no texto através de ordens que pretendem organizar a ação, descrevê-la ou prescrevê-la tem sido a prática no Manual do Professor e nos Cadernos do Professor da Proposta Curricular do Estado. Esses textos constroem o leitor-docente dizendo-lhe o que fazer como se suspeitassem da sua escassa formação e experiência e do que lhe falta saber. Por um lado, trata-se de um modo usual de dar eficácia ao que 
foi pensado como necessário para a transmissão de conhecimentos. Entretanto, é igualmente um meio de fixar uma fórmula de trabalho. Também há outros modos de dizer o que é pressuposto e condição da ação docente nos manuais de ensino de história. As formas amenizadas do modo imperativo no Referencial de Expectativas da área específica e nas Orientaçôes Curriculares e o insistente uso do verbo na sua forma infinitiva suavizam o texto mostrando cuidado com o modo de tratar o docente-leitor. Esse outro tipo de linguagem horizontaliza mais a relação autor-leitor contornando algo do exercício da autoridade funcional na linguagem.

Em muitas coleções recomendadas no PNLD-2008 e nos próprios referenciais e orientações curriculares, os esclarecimentos sobre os conteúdos da disciplina visam contribuir para se ver com maior clareza o que deve ser ensinado. Do mesmo modo que há expectativas quanto ao que é ensinado, esses documentos esperam que na maneira de ensinar o docente de história comente e explique a matéria, relacione os fatos, destaque conteúdos, demonstre os processos de mudança ao longo do tempo, informe sobre a atualidade de algumas questões históricas e estimule a aprendizagem do aluno. Se em alguma medida se pode concluir que a docência em história se caracteriza por fazer intervir nos atuais assuntos de interesse da juventude explicações racionais e exigências de convivência e participação social um dado interessante é a exígua presença de orientações relacionais que não as de ordem operacional: orientar, acompanhar, corrigir, estimular, avaliar, explicar, solicitar... Sobretudo é assim na parte específica dos manuais do professor. Já nos referenciais curriculares são freqüentes o recurso ao compromisso e à dedicação dos docentes, ao gosto pela matéria que lecionam e aos seus hábitos de leitura. Sobretudo, o Referencial, as Orientações, a Proposta Curricular e a série de Cadernos do Professor dão crédito aos qualificadores das interações do professor com a classe. Nessa direção, recomendam ao docente ler para a turma, debater com os estudantes, tornar possível a inclusão, apresentar os locais onde os alunos podem pesquisar estabelecer laços entre a escola e a comunidade. Orientações no sentido de lidar com a diversidade, considerar a realidade e os interesses dos alunos e de explicitar os costumes de um bom leitor somam ainda outras indicações para a abordagem da sala de aula. Ao professor, portanto, é solicitado que propicie situações de participação dos alunos na aula, conduza-a rotineiramente e favoreça a aprendizagem ativa, baseada num convívio positivo do professor com as suas classes. 
Apesar das diferenças de ênfase, é tão recorrente encontrar nos manuais didáticos quanto nos referenciais curriculares uma concepção da atividade do professor pautada em categorias como habilidade, competência e autonomia. Relacionar, compreender, explicar, acompanhar, orientar, corrigir e avaliar mostrara-se ser tanto expressões da ordem das habilidades quanto das competências que se solicitam dos docentes nesses tipos de publicação. $\mathrm{Na}$ análise que então realizei delas, concordei com autores que suspeitam de um mascaramento das reais intenções de propostas assim orientadas. Conforme avaliam Paim e Silva, o modo como termos do tipo habilidade, competência e autonomia estão incorporados aos dispositivos normativos evidenciam apenas uma linguagem de natureza prescritiva e funcional ${ }^{43}$. Incluir qualificativa como competência, compromisso e dedicação entre as orientações de procedimento e conduta lembram os leitores que há problemas nesse sentido e que ainda é preciso sublinhar as obrigações éticas e os valores profissionais associados à docência ao próprio docente.

Assim, as conclusões desta pesquisa resultaram do propósito de compreender os meios através dos quais a docência é representada, percebida e construída em documentos de orientação didática na área de História. Sobretudo lhes deram algum fundamento as formas como Chartier pensou os dispositivos discursivos e materiais da enunciação ${ }^{44} \mathrm{e}$ a maneira ativa a partir da qual Bakhtin percebeu o papel do destinatário na escolha dos procedimentos composicionais e dos meios linguísticos de um texto . Há nos referenciais curriculares uma série de artifícios para impor uma significação unívoca, para enunciar e produzir uma interpretação correta, que é também um modo de supor o exercício adequado da docência. Por essa razão, as relações entre as atuais políticas de currículo e o ensino de história levaram-me a pensar nos discursos para e sobre os professores como um instrumento essencial para compreender as estratégias de regulação da atividade da docência nessa disciplina. Sobretudo porque as representações da docência que autoridades e especialistas afirmam ao professor fazem parte integrante $\mathrm{da}$ realidade do magistério, definem um campo de lutas no qual os

\footnotetext{
${ }^{43}$ PAIM, Elison Antonio. (2007): "Do formar ao fazer-se professor", em MONTEIRO, A. M.; GASPARELLO, A. M.; MAGALHÃES, M. S. (org.). Ensino de história: sujeitos, saberes e práticas. Rio de janeiro: Mauad X, p. 157-171; SILVA, Monica Ribeiro (2008): óp., cit.

${ }_{45}^{44}$ Fundamentalmente, em CHARTIER, Roger. (2002): óp., cit.

Cf. BAKHTIN, Mikhail. (2006): óp., cit.
} 
manuais do professor e os referenciais curriculares tem uma pertinência operatória ímpar no ordenamento e na hierarquização da autoridade e das competências. Em conformidade com as análises de Chartier, espero ter conseguido mostrar na materialidade dos impressos analisados as marcas de sua produção, circulação e uso e, assim, apontado algo dos artifícios textuais que procuram construir o leitor-professor e determinar seus modos de ler. Do mesmo modo, utilizei Bakhtin para sublinhar que tanto a composição quanto o estilo do enunciado dependem da força e a influência do destinatário no discurso, pois, como o falante, o escritor percebe e representa para si os seus destinatários ${ }^{46}$.

\section{CONSIDERAÇÕES}

Penso dessa forma ter encontrado indícios suficientes para afirmar que a formatação do auxílio ao professor corresponde à ideia que se faz do seu trabalho em sala de aula. Quando nos manuais do professor ou nos referenciais curriculares os autores buscam orientar uma ação prática é ao seu leitor presumido - o professor - a quem se dirigem. Assim, a atenção para o estudo dos dispositivos e dos mecanismos a partir dos quais textos deste tipo materializam os leitores que esses autores têm em mente foi particularmente fecunda para se compreender a forma como eles expressam uma representação sobre a docência. Dessa perspectiva, o gênero didático e o estilo do discurso dos manuais do professor e das orientações curriculares constituem signos muito visíveis de uma determinada compreensão do exercício do magistério. No geral, o estudo da forma de empregar os tempos e modos verbais, os pronomes, os advérbios de circunstância e os conectivos confirma uma tradição de análise dos livros didáticos e das políticas curriculares já consolidada e que critica o quanto esses dois tipos de publicação reduzem o papel do professor a de um mero executor de tarefas ${ }^{47}$. Nessa direção, também é possível perceber que os manuais do professor e os referenciais curriculares assentam uma percepção de que os professores não tiveram formação adequada. No entanto, não vão apenas nesse sentido as considerações que se pode fazer sobre as representações acerca da docência instauradas pelos seus textos. Sobretudo, a pesquisa também procurou também reconhecer as formas institucionais e objetivadas em virtude das quais se vem marcando e significando simbolicamente o exercício da docência em História.

\footnotetext{
${ }_{47}^{46}$ Cf. BAKHTIN, Mikhail. (1992): óp., cit. BAKHTIN, Mikhail (2006): óp., cit.

${ }^{47}$ Cf. PROST, Antoine (1996): As palavras, in RÉMOND, R. (org.) Por uma bistória política. Rio de Janeiro: FGV Editora, pp. 295-330.
} 
No quadro compreensivo que então se pode propor a respeito das exigências que se procura fazer o docente interiorizar, inventariei primeiro as estratégias e rotinas tidas como constitutivas da prática do ensino de História pelos manuais do professor e pelos referenciais curriculares. Principalmente, há operações que sob a justificativa de tornar os utensílios conceituais da história menos opacos ao entendimento dos docentes e alunos visam atingir o fundo e a forma da narração histórica em sala de aula. Por um lado, predominam orientações para organizar as rotinas de elaboração visual das aprendizagens (cartazes, painéis e construção de materiais), de discussão e reflexão (debates, seminários e entrevistas) ou de síntese (exposições, resumos) e as dinâmicas de jogos e representações. Por outro, percebe-se a elaboração de abordagens didáticas cada vez mais capazes de refletir os avanços da ciência histórica e a incorporação de soluções pedagógicas propostas para o ensino de história. Encabeçam a lista de orientações de fundo as indicações para o professor problematizar a realidade social através da análise do passado, insistindo no papel da história como iluminação do passado sobre o presente. Também se recomenda acompanhar os momentos iniciais da formação da consciência crítica, participar de maneira ativa do processo de percepção e formação dos valores constituintes da cidadania e contextualizar uma produção cultural ou documento, discutir discursos políticos nas aulas e confrontar idéias do seu texto. Orientações para o trabalho com fontes são igualmente recorrentes nos manuais do professor e nos referenciais curriculares. Tem importado tratar da seleção e crítica de textos históricos de diversos gêneros (crônicas, discurso político, texto jornalístico) de imagens (mapas, obras de arte, charges, fotografia, filmes, gravuras) e representações gráficas e estatísticas com finalidades didáticas. Ciosos da solidez teórico-metodológica do trabalho docente, os materiais de orientação didática sublinham que também o ensino de história deve observar o rigor historiográfico no tratamento das fontes ${ }^{48}$. Outro conjunto de recomendações que é especifica para o ensino de história diz respeito às reflexões sobre o tempo. Em relação às conexões temporais da agência humana do passado que o estudo da história produz, os manuais didáticos e os referenciais curriculares basicamente orientam o docente recorrer à linha cronológica e trabalhar com diferentes concepções de tempo histórico. Sobre as temporalidades, as recomendações são tão procedimentais quanto a respeito das fontes:

\footnotetext{
${ }^{48}$ Principalmente em SÃO PAULO (Município). 2006. Referencial de expectativas para 0 desenvolvimento da competência leitora e escritora no ciclo II: caderno de orientação didática de História. São Paulo, SME/DOT e SÃO PAULO (Estado). 2008. óp., cit.
} 
comparar e relacionar, criar estratégias de leitura favoráveis para a compreensão do aluno, propor projetos de trabalho, promover questões e utilizar o material didático.

De ordem mais geral, as instruções para a gestão das atividades da sala de aula seguem numa lógica que pressupõe o domínio de uma série de habilidades e competências por parte do professor. Assim, as ações de estimular, orientar, valorizar, esclarecer, auxiliar e avaliar o aluno, selecionar, organizar e explicar o conteúdo ou de lidar com a diversidade, questionar, solicitar, debater, problematizar e planejar o trabalho constituem referências consolidadas para o exercício do magistério. Há também passagens em que os manuais didáticos e os referencias curriculares apostam na criatividade do professor, recomendando que o docente crie situações de trabalho e estratégias didáticas e de leitura. Também são reconhecidos como tarefas criativas os ajustes e as adaptações que se espera que o professor realize. As publicações dirigidas aos docentes invariavelmente consideram que no conjunto o trabalho em sala de aula apenas se completa com o registro dos processos e resultados. Tanto quanto as propostas de reorientação curricular, os manuais do professor insistem na necessidade de registrar o que o docente for realizando e os resultados conseguidos.

Outra característica do exercício da docência que os manuais do professor e os referencias curriculares formalizam por meio de seus dispositivos narrativos e suas estratégias de persuasão ou de demonstração diz respeito à interação com os alunos. Insistentemente, recomenda-se ao docente ler para a turma, debater com os estudantes, tornar possível a inclusão, apresentar os locais onde os alunos podem pesquisar estabelecer laços entre a escola e a comunidade. Fazer o professor motivar o aluno com práticas compreensíveis e significativas somam mais indicações para a abordagem da sala de aula. Trata-se de uma série de orientações que se apóiam em valores da época: o atrativo das fontes, a facilidade do que está pronto para consumir, o sucesso certo e instantâneo que gratifica . E, em torno dessa concepção do trabalho que deve ser realizado pela escola, fazer os alunos produzirem, providenciarem, trocarem informações ou questionarem, entre tantos outros procedimentos de aprendizagem estabelece a atual especificidade do exercício da docência .

\footnotetext{
${ }^{49}$ Sobre a problemática do presente e o ensino de história ver, sobretudo, HOBSBAWM, Eric (1991): A era dos extremos. São Paulo, Cia das Letras.

Cf. ARROYO, Miguel. (2004): O ofício de mestre. Petrópolis, Vozes.
} 
Ainda quanto às interações que os manuais e os referenciais esperam ocorrer na sala de aula existem especificidades de acentuação. Nos manuais não há o que encontrar acerca das formas de organização da classe e o controle da sua disciplina, os gestos, as maneiras de fazer e os procedimentos de conduta entre outras tantas ações implícitas da aula. Nesse tipo de impresso predomina a preocupação com as questões metodológicas da matéria, os processos de aprendizagem, e as modalidades de atividade e avaliação. Já nas orientações curriculares, as recomendações abrangem um domínio de procedimentos entendido como de gestão da sala de aula. As formas de conduzir a classe e o controle da sua disciplina, os gestos, as maneiras de fazer e os procedimentos de conduta entre outras tantas ações implícitas da aula são assumidas como diretrizes. Pareceu ser uma questão específica das atuais propostas de reorientação curricular da cidade e do Estado de São Paulo promover estratégias de abordagem da classe e de condução das suas atividades.

Especialmente os referencias curriculares compreendem a função docente como de mediação. Por um lado, insistem que o professor assuma a sua tarefa de mediador de leitura e, assim, o papel daquele que desvela questões e problemas. Por outro, as orientações curriculares do Estado de São Paulo e da prefeitura da capital reconhecem que as competências e habilidades desenvolvidas na escola dependem da qualidade das mediações realizadas pelo professor. Nesse sentido, a cuidadosa atenção que dispensam a alguns qualificativos da docência é relevante para a compreensão das representações que agentes determinados do poder público fazem das práticas docentes. Sobretudo a responsabilidade pelo comando do espaço da escola, o compromisso e a dedicação são os atributos principais por meio dos quais os referenciais curriculares qualificam o trabalho do professor. Conforme adverte Roger Chartier, expedientes desse tipo contribuem para marcar de modo visível a representação social de um grupo ou classe .

As pesquisas sobre as maneiras do professor realizar seu trabalho em sala de aula e dele usar os materiais didáticos mostram que, no fazer cotidiano, os docentes tornam possíveis variações em relação ao esperado, ao prescrito e planejado. Uma série de estudos tem documentando expedientes de ensino e administração do dia-a-dia da sala de aula que impedem tomar o professor como simples executor de modelos prescritos.

${ }^{51}$ CHARTIER, Roger. óp., cit, p. 183. 
Diferentemente das análises que operam com a distinção entre a fala e o saber competente do especialista e os receptores do conhecimento, cuja participação no saber é visto como mera ilusão, essa literatura reconhece os espaços de ação que o docente se autoriza ter em relação às orientações prescritas. Assim, e muito de acordo com o entendimento de Michel de Certeau, vem-se percebendo que os meios de fabricar autoridade e conformidade não escapam aos artifícios e subterfúgios de resistência das pessoas comuns diante dos empreendimentos que queiram desapossálas e domesticá-las ${ }^{52}$. Seguindo essa orientação de pesquisa, abordei os manuais dos professores das coleções didáticas de história recomendadas pelo PNLD-2008, os Referenciais Curriculares da Secretaria Municipal de Educação de São Paulo e a Proposta Curricular do Estado de São Paulo como fontes para o estudo das formas como se vêm tratando os paradigmas organizadores do discurso sobre as práticas de ensino.

\section{REFERÊNCIAS}

ARROYO, Miguel. (2004): O oficio de mestre. Petrópolis, Vozes.

AUSTIN, John. (1990): Quando dizeré fazer. Porto Alegre: Artes Médicas.

AUSTIN, John. (1993): Sentido e percepção. São Paulo, Martins Fontes.

BAKHTIN, Mikhail. (2006): Estética da criação verbal. São Paulo, Marins fontes.

BAKHTIN, Mikhail. (1993): Marxismo e filosofia da linguagem: problemas fundamentais do método sociológico na ciência da linguagem. $6^{\mathrm{a}} \mathrm{Ed}$. São Paulo.

BARTHES, Roland. (2002): O prazer do texto. $3^{\text {a }}$ edição. São Paulo, Perspectiva.

BERGMANN, Klaus. (1989): “A história na reflexão didática”. Revista Brasileira de História, V. 9, No 19. São Paulo.

BORNE, Dominique. Comunidade de memória e rigor crítico. In.: BOUTIER, J; JULIA, D. (org.). Passados recompostos: campos e canteiros da História. Rio de Janeiro: UFRJ; FGV, p.133-141, 1998.

BRASIL (MEC-FNDE). (2007): Edital de convocação para inscrição no processo de avaliação e seleção de obras didáticas a serem incluídas no

${ }^{52}$ De CERTEAU, Michel. (1994): A invenção do cotidiano. Vol. 01 - Artes de fazer. São Paulo, Vozes. 
Guia de Livros Didáticos para os anos finais do ensino fundamental. ftp://ftp.fnde.gov.br/web/editaislicitações/edital_pnld-2008pdf., 63 fls. Acesso: 09 jan. 2007.

BRASIL (MEC-FNDE). (2007): Guia de livros didáticos PNLD 2008: História. Brasília, MEC.

De CERTEAU, Michel. (1994): A invenção do cotidiano Vol. 01 - Artes de fazer. São Paulo, Vozes.

CHARTIER, Anne-Marie. (2007): Práticas de leitura e escrita: história e atualidade. Belo Horizonte, Autêntica.

CHARTIER, Roger. (1991): “O mundo como representação". Estudos Avançados, 11 (5).

CHARTIER, Roger. (2002): À beira da falésia: a história entre certezas e inquietude. Porto Alegre, Editora da Universidade/UFRGS.

CHAUÍ, Marilena. (1989): Cultura e democracia. São Paulo, Cortez.

CIAMPI, Helenice et. al.(2009): “O currículo bandeirante: a proposta curricular de história no estado de São Paulo”, em Revista Brasileira de História. São Paulo.

FIORIN, José Luís. (2008). As astúcias da enunciação: as categorias de pessoa, espaço e tempo. $2^{\text {a }}$ ed. São Paulo, Ática.

FONSECA, T. N. L.(2006): História e ensino de história. $2^{\mathrm{a}}$ Ed. Belo Horizonte, Autêntica.

FORQUIN, Jean-Claude. (1992): "Saberes escolares, imperativos didáticos e dinâmicas sociais" em Teoria \& Educação. No 05.

FOUCAULT, Michel. (2003): Estratégia, poder-saber. Rio de Janeiro: Forense

FOUCAULT, Michel. (1998): A ordem do discurso. São Paulo, Loyola.

GOODSON, Ivor. (1995): Currículo: teoria e história. Petrópolis-RJ: Vozes.

GOODSON, Ivor. (2008): As políticas de currículo e de escolarização. São Paulo, Vozes.

GOODSON, Ivor. (1988): The making of curriculum. Londres, Falmer Press.

GREIMAS, Algirdas Julien. (1973): Semântica estrutural. São Paulo, Cultrix, Edusp. 
HOBSBAWM, Eric. (1991): A era dos extremos. São Paulo, Cia das Letras.

LEFORT, Claude. (1983): A invenção democrática: os limites da dominação totalitária. São Paulo, Brasiliense.

MATELA, R. C. P. O. (1994): professor de história e o livro didático: uma relação delicada. Niterói, 1994. Dissertação (Mestrado) - Educação. Universidade Federal Fluminense.

McKENZIE, D. F. (1986): Bibliography sociology os texts, panizzi lectures. Londres, The British Library.

MODERNA. Projeto Araribá: História. 4vol. Manual do Professor, São Paulo: Moderna, 2006.

MOREIRA, A. F. (1997): Currículo: questões atuais. Campinas, Papirus.

PAULILO, André Luiz. (2010): Os modos de enunciação nos manuais de ensino para professor de história. Topoi, vol. 11, Nº 21.

SILVA, Monica Ribeiro. (2008): Currículo e competências: a formação administrada. São Paulo, Cortez.

SEARLE, John. (1995): Expressão e significado: estudos da teoria dos atos de fala. São Paulo, Martins Fontes.

SEARLE, John. (1981): Os actos de fala: um ensaio de filosofia da linguagem. Coimbra, Livraria Almedina. Saraiva.

SCHEFFLER, Israel. (1974): A linguagem da educação. São Paulo, EDUSP,

VIDAL, Diana. (2005): A cultura esclar. Campinas, Autores Associados.

PAULILO, André Luiz. (2011): “Os manuais do professor das coleções didáticas e os referenciais curriculares como fontes de pesquisa em educação" en: Revista Historia de la Educación Latinoamericana N. 16, Tunja, Universidad Pedagógica y Tecnológica de Colombia, RUDECOLOMBIA, SHELA- HISULA pp. 175-198 